\title{
Preparation of Platinum-based 'Cauliflower Microarrays' for Enhanced Gas Sensing
}

\author{
Ghulam Hussain, ${ }^{\mathrm{a}}$ Leigh Aldous ${ }^{\mathrm{b}}$ and Debbie S. Silvester, ${ }^{\mathrm{a},}$
}

\begin{abstract}
${ }^{a}$ Curtin Institute for Functional Molecules and Interfaces, School of Molecular and Life Sciences, Curtin University, GPO Box U1987, Perth,6845,WA, Australia.; E-Mail: d.silvester-dean@curtin.edu.au.

${ }^{b}$ Department of Chemistry, King's College London, 7 Trinity Street, London, SE1 1DB, UK.

* Author to whom correspondence should be addressed; E-Mail: d.silvester-dean@curtin.edu.au; Tel.: +61-08-9266-7148; Fax: +61-08-9266-2300
\end{abstract}

\begin{abstract}
:
In amperometric gas sensors, the flux of gas to electrode surfaces determines the analytical response and detection limit. For trace concentration detection, the resulting low current prevents the miniaturisation of such sensors. Therefore, in this study, we have developed repeating arrays of nanostructures which maximise flux towards their surface. Unique platinum 3D cauliflower-shaped deposits with individual floret-shaped segments have been produced in a single step electrodeposition process. The confined walls of recessed microelectrode arrays $(10 \mu \mathrm{m}$ in diameter, 90 electrodes) are utilized to produce these structures with a high surface area. Distinct segments are observed, with the gaps corresponding to electrodes adjacent in the microarray; thus the majority of the deposits face the primary diffusion zones. The sizes and shapes of the deposits are characterized by scanning electron microscopy (SEM) and atomic force microscopy (AFM) and the largest structures are found to be $22 \pm 1 \mu \mathrm{m}$ in width and $7.9 \pm 0.2$ $\mu \mathrm{m}$ in height over the microhole. These modified electrodes are employed to detect ammonia gas using the room temperature ionic liquid 1-ethyl-3-methylimidazolium bis(trifluoromethylsulfonyl)imide, $\left[\mathrm{C}_{2} \mathrm{mim}\right]\left[\mathrm{NTf}_{2}\right]$, as an electrolyte. Current responses on the cauliflower arrays were seven times higher for linear sweep voltammetry and ca. 12 times higher for chronoamperometry, relative to the bare microrrays, and limits of detection were less than 1 part per million of ammonia (gas phase concentration). This work highlights the use of modified microarrays with highly accessible 3D structures for enhanced electroanalytical detection of analyte species at ultra low concentrations.
\end{abstract}

Keywords: cauliflower; 3D nanostructures; electrodeposition; voltammetry; room temperature ionic liquids; limit of detection; ammonia oxidation 


\section{Introduction}

The detection and quantification of low concentrations of toxic gases, such as ammonia $\left(\mathrm{NH}_{3}\right)$, is of huge importance in a range of applications [1]. For example, $\mathrm{NH}_{3}$ is widely used in the manufacture of acids, fertilizers, explosives, in water treatment, as a catalyst and reagent in many chemical processes, and in refrigeration systems, among other applications [2]. However, it is toxic to humans at concentrations above $500 \mathrm{ppm}$ and the Occupational Health and Safety permissible exposure limit (OHSA PEL) is 25 ppm in the gas phase [2]. As a result of the wide use of ammonia and its high toxicity, various sensors for ammonia are commercially available, including amperometric sensors [3] - where electrical current is correlated with gas concentration. Room temperature ionic liquids (RTILs) are being investigated over the last decade as replacement solvents in amperometric gas sensors [4-7] due to their many advantages, including low volatility, wide electrochemical windows, high chemical and thermal stability, and good gas solvation ability. However, RTILs are typically are more viscous than traditional solvents, which results in slower diffusion coefficients of analyte species [8], and often leads to smaller observed currents. Therefore, for ionic liquid-based electrolytes, it may be necessary to increase the surface area of the sensing electrode in order to detect very low concentrations of analyte species.

Different materials with large surface areas, including noble metal nanoparticles (e.g. platinum, gold, silver) [9-11], semiconductor nanoparticles (e.g. zinc oxide, tin oxide),[9] and carbon materials such as carbon nanotubes [12] have been employed to enhance the sensitivity of the working electrode surface. Over the last decade, nanostructures with different shapes and geometries such as nanowires [13], nanorods [14], honeycomb [15], mesoporous [16], and dendritic structures [17, 18] have been reported. Nanostructures with two-dimensional (2D) and three-dimensional (3D) architectures have received significant attention due to their large electroactive surface areas, excellent conductivity, and efficient electrocatalytic ability $[19,20]$. To date, significant progress has been made to produce morphologies such as nanoflowers, nanopetals, nanourchins, cauliflowers, raspberries etc. [21-25]

The most commonly encountered methods used to produce these structures are: chemical vapour deposition (CVD), physical vapour deposition (PVD), galvanic displacement, or electrodeposition [23]. For example, Kong et al. [19] produced nanocube-aggregated cauliflower-like copper hierarchical 3D nanostructures by electroless deposition and used the deposits to study the electrocatalytic reduction of oxygen. Zhang et al. [26] developed a thin film of 3D hierarchical $\mathrm{ZnO}$ nanostructures with different shapes such as nanourchins and nanoflowers using a simple hydrothermal approach, and employed these for photocatalytic studies of organic dyes. Chen et al. [27] synthesized 3D-shaped nanoflowers of tin oxide semiconductor using thermal pyrolysis of a tin organometallic precursor. Nizhad et al. [28] produced gold nanostructures of various shapes and geometries on a semiconductor wafer, such as indium phosphide and gallium arsenide via galvanic displacement reactions. The synthesis of these 
nanostructures with 2D or 3D architectures involve either the use of semiconductor materials, expensive fabrication techniques (CVD or PVD), or require complicated methodologies to produce the modified surfaces.

Electrodeposition is a highly competitive alternative technique to those described above, due to its simplicity, relatively low cost, and low power consumption. Additionally, a wide range of controllable parameters can be varied to produce the desired size of deposit. Electrodeposits of noble metals (e.g. platinum or gold) typically produce nanostructures or sphere-like nanoparticles. There are limited studies on the direct electrodeposition of pure noble metals into high surface area 3D nanostructures in a single step. Jayashree et al. [29] prepared silicon-based membrane electrodes by the electrodeposition of pure $\mathrm{Pt}$ and Pd into dendritic and spherical shapes, and employed these for the electrocatalytic oxidation of formic acid in micro fuel cells. Tiwari et al. [30] electrodeposited Pt-nanopetals onto highly ordered silicon nanocones using anodized aluminum as a template, and used this for the electrocatalytic oxidation of methanol in fuel cell applications. The concentration of metal precursor is believed to affect the morphology of the deposits [31, 32]. In general, a low concentration of noble metal precursor produces nanoparticles, while a higher concentration produces dendritic shaped nanostructures $[21,31]$.

We have recently reported the use of commercial recessed microarray thin-film electrodes covered with a droplet $(2 \mu \mathrm{L})$ of an essentially non-volatile ionic liquid for the electrochemical quantification of ammonia gas [33]. Careful filling of the recessed Pt microarrays with electrodeposited Pt was able to enhance flux, resulting in extremely low limits of detection (20 ppb) [33], far below the permissible exposure limit for ammonia (25 ppm) [34]. However, further enhanced flux is required for both faster response times, and for achieving even lower limits of detection; both are relevant to the field detection of toxic gases, volatiles from improvised explosive devices, and of potent chemical weapons, etc. [35, 36]

In this work, we have investigated the formation of 3D cauliflower-shaped deposits, in a single electrochemical step. Crucially, the confined walls of the recessed $\mu$-holes contained within microarray thin film electrodes (MATFEs) supported the growth of such structures, and also resulted in regular arrays. This allowed full utilization of the deposits by virtue of clear diffusion zones surrounding the deposits. These decorated microarrays were then employed for the electrochemical sensing of ammonia gas in room temperature ionic liquids (RTILs), to highlight the significantly enhanced current responses and improved sensitivity towards the gas, made possible by the electrode structuring.

\section{Materials and Methods}

\subsection{Chemical Reagents.}

Ethanol (EtOH, 99\%), acetone (99\%), sulfuric acid (98\% w/w [18.4 M]) and zinc chloride $\left(\mathrm{ZnCl}_{2}, 40 \%\right.$ w/v, used as a soldering flux for connecting wires with electrodes), and chloroplatinic acid hydrate 
$\left(\mathrm{H}_{2} \mathrm{PtCl}_{6} \cdot \mathrm{xH}_{2} \mathrm{O}\right.$, trace metal basis, $\left.\geq 99.9 \%\right)$ were from Sigma-Aldrich. The room temperature ionic liquid (RTIL) 1-ethyl-3-methylimidazolium bis(trifluoromethylsulfonyl)imide $\left(\left[\mathrm{C}_{2} \mathrm{mim}\right]\left[\mathrm{NTf}_{2}\right]\right)$, was purchased from Merck (Kilsyth, Victoria, Australia), at ultra-high purity electrochemical grade. All chemicals were commercially available and used as received. Ultrapure water with a resistance of $18.2 \mathrm{M} \Omega \cdot \mathrm{cm}$ was prepared by an ultrapure water purification system (Millipore Pty Ltd., North Ryde, NSW, Australia). Acetonitrile (MeCN, >99.8\%, Fischer Scientific) was used for washing the electrodes before and after use. An ammonia gas cylinder (500 ppm, in nitrogen) was purchased from CAC gases (Auburn, NSW, Australia). Nitrogen gas (for further dilution of $\mathrm{NH}_{3}$ ) was obtained from a $\geq 99.99 \%$ high purity, compressed nitrogen cylinder from BOC gases (Welshpool, WA, Australia).

\subsection{Electrochemical Experiments}

All experiments were performed using a PGSTAT101 Autolab potentiostat (Eco Chemie, Netherlands) interfaced to a PC with Nova 1.11 software, at laboratory room temperature $(294 \pm 1 \mathrm{~K})$ inside an aluminium Faraday cage present in the fume cupboard to reduce electrical interference. Platinum $(\mathrm{Pt})$ microarray thin-film electrodes (MATFEs, Micrux Technologies, Oviedo, Spain, ED-mSE1-Pt) consisted of a $1 \mathrm{~mm}$ diameter Pt working electrode (150 nm thickness) on a Pyrex glass substrate covered with a layer of SU-8 polymer. $90 \mu$-holes of $10 \mu \mathrm{m}$ diameter were made in the SU-8 layer to create 90 recessed microelectrodes, with a center-to-center distance of $100 \pm 1 \mu \mathrm{m}(10 \times$ diameter $)$ and depth of $3 \pm 0.5 \mu \mathrm{m}$. The planar electrode device also contained inbuilt Pt thin film counter and reference electrodes, deposited close to the working electrode, to enable the use of very small sample volumes (e.g. 1-5 $\mu \mathrm{L}$ ).

The MATFEs were electrochemically activated in $0.5 \mathrm{M} \mathrm{H}_{2} \mathrm{SO}_{4}$ (aq) by scanning the potential between -0.27 and $+1.4 \mathrm{~V}$ vs an external $\mathrm{Ag} / \mathrm{AgCl}(0.1 \mathrm{M} \mathrm{KCl})$ reference electrode (BASi, Indiana, USA) and Pt coil counter electrode (Goodfellow, Cambridge Ltd., UK) at a sweep rate of $500 \mathrm{mVs}^{-1}$ for ca. 300 cycles. The electrodes were then washed in ultrapure water and dried under a nitrogen stream. Before gas sensing experiments, the recessed $\mu$-holes were filled with Pt-deposits of 2D Pt-nanostructures and 3D Pt-cauliflowers. During the deposition process, different parameters were varied, such as the concentration of $\mathrm{Pt}$ complex, deposition potential, rate of mass transfer, and deposition time. The potential was held at the open circuit potential (OCP, $+0.75 \mathrm{~V}$ vs stable $\mathrm{Ag} / \mathrm{AgCl}$ reference electrode), then applied at two different regions: (i) underpotential $(-0.025,-0.05 \mathrm{~V})$ to kinetically control the nucleation and growth of $\mathrm{Pt}$ [37], and (ii) overpotential (-0.2 V) to produce instant nucleation and growth of Pt-deposits [38-40]. Concentrations of $5 \mathrm{mM}$ or $20 \mathrm{mM} \mathrm{H}{ }_{2} \mathrm{PtCl}_{6}$ in $0.5 \mathrm{M} \mathrm{H}_{2} \mathrm{SO}_{4}$ were employed. Deposition times of 10, 60 and 300 seconds were employed, but 300 seconds was found to be optimum and was employed for all experiments reported in this work. The rate of mass transfer was controlled by either no stirring or using a fast rate of magnetic stirring. The resulting modified electrodes were named: 
(a) filled MATFE, (b) 'cauliflower A' MATFE, and (c) 'cauliflower B' MATFE. The detailed deposition procedures are given below.

Procedure 1: For filled MATFEs, a stirred $\mathrm{N}_{2}$-saturated solution of $5 \mathrm{mM} \mathrm{H}_{2} \mathrm{PtCl}_{6}$ in $0.5 \mathrm{M} \mathrm{H}_{2} \mathrm{SO}_{4}$ was used. Constant-potential deposition was employed, stepping the potential from the OCP $(0.75 \mathrm{~V})$ to the underpotential region at $-0.05 \mathrm{~V}$ [41], near the start of the second reduction peak, and holding for 300s. The nucleation and growth of Pt-deposits is under kinetic control at this potential, and strong magnetic stirring was employed to ensure a fast rate of mass transfer.

Procedure 2: For 'cauliflower A' MATFEs, a $\mathrm{N}_{2}$ saturated solution of $20 \mathrm{mM} \mathrm{H}_{2} \mathrm{PtCl}_{6}$ in $0.5 \mathrm{M} \mathrm{H}_{2} \mathrm{SO}_{4}$ was used. Constant-potential deposition from the OCP $(0.75 \mathrm{~V})$ to an overpotential $(-0.2 \mathrm{~V})$ was employed for 300 seconds. Instantaneous nucleation and growth of the Pt-deposits occurred, forming cauliflower type structures. The solution was unstirred to ensure only a moderate rate of flux.

Procedure 3: For 'cauliflower B' MATFEs, the protocol was the same as procedure 2, except the deposition was carried out under fast magnetic stirring to ensure a fast rate of flux.

Prior to starting gas sensing experiments, the modified MATFEs were electrochemically activated in $0.5 \mathrm{M} \mathrm{H}_{2} \mathrm{SO}_{4}$ (aq) by scanning the potential between -0.27 and $+1.4 \mathrm{~V}$ vs. an external $\mathrm{Ag} / \mathrm{AgCl}(0.1 \mathrm{M}$ $\mathrm{KCl}$ ) reference electrode and $\mathrm{Pt}$ coil counter electrode at a sweep rate of $500 \mathrm{mVs}^{-1}$ for ca. 5 cycles to ensure there was no oxide layer or chloride ions $\left(\mathrm{Cl}^{-}\right)$adsorbed on the active sites [41]. The electroactive surface area (ESA) of the Pt-deposited MATFEs (taken after gas sensing experiments in RTILs) was calculated from the area under the hydrogen adsorption/desorption peaks in $0.5 \mathrm{M} \mathrm{H}_{2} \mathrm{SO}_{4}$ using standard methods $[41,42]$.

For gas sensing experiments, the Pt-deposited MATFEs were placed into a modified rubber stopper and inserted into the glass cell (a modified version of a T-cell) [43-45]. $2 \mu \mathrm{L}$ of RTIL was dropcast on the Pt-deposited MATFEs. Prior to the introduction of ammonia, the cell was purged with nitrogen to remove dissolved gases and impurities. When the baseline was stable (after ca. 20 minutes), ammonia gas was introduced into the cell and continuously flowed over the electrode.

\subsection{Gas Mixing System.}

In order to obtain different concentrations of ammonia, $500 \mathrm{ppm}$ ammonia gas was diluted with nitrogen gas through gas mixing system as reported by Lee et al. [45] which consisted of two digital flow meters (0-1.0 L/min, John Morris Scientific, NSW, Australia), one connected with analyte gas cylinder $\left(\mathrm{NH}_{3}\right)$ and other with nitrogen cylinder through PTFE tubing via a Swagelok T-joint (Swagelok, Kardinya, WA, Australia). The mixture of both desired gases $\left(\mathrm{NH}_{3} / \mathrm{N}_{2}\right)$ was then passed through an additional gas-mixing segment [45] to increase turbulence and to ensure adequate mixing of both gases. The relative flow rates were used to calculate the different concentrations of ammonia introduced into the T-cell. 


\subsection{Electrode Imaging.}

Scanning electron microscopy (SEM) was performed on the working electrodes of the unmodified and the three Pt-deposited MATFEs. SEM Images were obtained using MIRA3 (MIRA VP-FESEM), with an accelerating voltage of $5.0 \mathrm{kV}$. Atomic force microscopy (AFM) was performed using WITech alpha 300SAR instrument on the unmodified and Pt-deposited MATFEs to image the geometry, depth, and filling of the $\mu$-holes, and the size of the 3D cauliflowers was measured using WITech Project Four data analysis software.

\section{Results and discussion}

\subsection{Electrodeposition of Pt 2D Nanostructures and 3D Cauliflowers.}

In order to ensure the correct potential for electrodeposition on the MATFEs, cyclic voltammetry (CV) was first performed in a solution of $20 \mathrm{mM} \mathrm{H}_{2} \mathrm{PtCl}_{6}$ in $0.5 \mathrm{M} \mathrm{H}_{2} \mathrm{SO}_{4}$ at $100 \mathrm{mVs}^{-1}$, as shown in Fig. 1. Initially, on the first cycle (black CV), two reduction features were observed at $\sim+0.02 \mathrm{~V}$ (peak I) and $0.17 \mathrm{~V}$ (peak II), described by the following equations [41, 46, 47]:

$$
\begin{array}{ll}
\text { Peak (I) } & \mathrm{Pt}^{\mathrm{IV}} \mathrm{Cl}_{6}{ }^{2-}+2 \mathrm{e}^{-} \rightarrow \mathrm{Pt}^{\mathrm{II}} \mathrm{Cl}_{4}{ }^{2-}+2 \mathrm{Cl}^{-} \\
\text {Peak (II) } & \mathrm{Pt}^{\mathrm{II}} \mathrm{Cl}_{4}{ }^{2-}+2 \mathrm{e}^{-} \rightarrow \mathrm{Pt}^{0}+4 \mathrm{Cl}^{-}
\end{array}
$$

The shape of these reduction features are more steady-state in shape compared to the typical behavior on macrodisk electrodes $[47,48]$, attributed to the radial diffusion occurring at the microelectrodes in the array. A further reduction process (III) was observed at $-0.25 \mathrm{~V}$ that corresponds to the evolution of bulk hydrogen [41]. On the reverse scan, the oxidation peak at ca. -0.05 V corresponds to hydrogen desorption. It is noted that hydrogen adsorption peaks may also be present at a similar potential to peak (II), but they are reportedly hard to differentiate on a Pt surface in acidic media [41, 47]. On the tenth cycle (red CV), peak (V) was observed, which corresponds to the oxidation of Pt to Pt-oxide. This peak has a corresponding reduction peak (VI), attributed to the reduction of Pt-oxide [42, 49, 50]; these enhanced features are the result of rough Pt deposits growing on the Pt electrodes.

We have previously utilized 'filled' MATFEs [33], although their preparation has not been discussed before in detail. Here, electrodeposition of Pt into the $\mu$-holes of the MATFE was performed in $5 \mathrm{mM} \mathrm{N}$-saturated $\mathrm{H}_{2} \mathrm{PtCl}_{6}$ at $-0.05 \mathrm{~V}$ vs $\mathrm{Ag} / \mathrm{AgCl}$ using constant potential deposition in a single electrochemical step. This low potential corresponds to a kinetically controlled regime, where instantaneous nucleation is believed to occur. Thus, growth of dense Pt deposits occurs, gradually filling up the $\mu$-holes. Fig. 2(a) shows the current transient and corresponding electrochemical parameters for the 2D deposition of $\mathrm{Pt}$ in the $\mu$-holes; current increases with time as a result of filling the $\mu$-holes and thus enhancing flux. 
In this study, we have also investigated deposition at a higher potential $(-0.20 \mathrm{~V})$ and using a higher concentration of $\mathrm{Pt}$ precursor $\left(20 \mathrm{mM} \mathrm{H}_{2} \mathrm{PtCl}_{6}\right)$. As the higher potential corresponds to progressive nucleation [41], rougher Pt electrodeposits are expected. Fig. 2(b) highlights the current transient for electrodeposition under quiescent conditions, and Fig. 2(c) the same but for stirred conditions. Under these conditions, current gradually increased in the first $100 \mathrm{~s}$, corresponding to filling of the $\mu$-holes. After $c a .100$ seconds, oscillation/spikes in the current signals can be seen, which indicates the beginning of rough Pt growths over the edges of the $\mu$-holes. As the deposition time proceeds from 100 seconds to 300 seconds, the intensity of the current spikes increase, corresponding to the growth of protruding 'Ptcauliflowers' (as demonstrated later). While stirring does not influence the filling of the $\mu$-holes, it results in larger current oscillations in the $100-300 \mathrm{~s}$ region, due to the faster rate of mass transfer, resulting in larger 3D Pt deposits.

\subsection{Characterization of Pt 2D Nanostructures and 3D Cauliflowers Using SEM and AFM.}

All three 2D and 3D Pt-modified MATFEs and an unmodified recessed MAFTE were analyzed using scanning electron microscopy (SEM) and atomic force microscopy (AFM). Fig. 3 shows SEM images for all four surfaces employed. The SEM image of the recessed MATFE (Fig. 3a) shows an array of recessed $\mu$-holes (90 in total over the whole array) made in an SU-8 polymer layer. The inset to Fig. 3a shows a zoomed in image of one $\mu$-hole with a diameter of $10 \mu \mathrm{m}$. The depth of the $\mu$-hole is $2.8 \mu \mathrm{m}$, confirmed from the depth profile of an AFM 3D image (see Fig. 4a) which is within the manufacturers statement of $3 \pm 0.5 \mu \mathrm{m}$. Fig. $3 \mathrm{~b}$ shows a SEM image of a filled MATFE, achieved by depositing $2 \mathrm{D}$ Pt-nanostructures at a lower potential $(-0.05 \mathrm{~V})$. The inset shows a close-up image of a filled $\mu$-hole with a dense $2 \mathrm{D} \mathrm{Pt}$ electrodeposit. AFM characterization revealed that the $\mu$-holes were $c a$. $70 \%$ filled (with slightly more at the edges) with a depth of ca. $0.9 \pm 0.1 \mu \mathrm{m}$ from the surface (see Fig. $4 \mathrm{a}$ ), consistent with that previously reported [33]. This amount of filling is enough to produce enhanced radial diffusion of analyte species at the edges of the $\mu$-holes, rather than linear diffusion within the recession, enhancing the voltammetric response (see later).

The SEM image of 'cauliflower A' MATFE (Fig. 3c) shows an array of 3D cauliflower shaped Pt nanostructures with individual bud-type segments, with each cauliflower having an average diameter of $18 \pm 0.5 \mu \mathrm{m}$. The formation of this unique shape occurred due to the higher concentration of Pt precursor [21] and the use of a higher potential for the deposition $(-0.2 \mathrm{~V})$ to produce progressive growth of nanoparticles. As the amount of deposit increases within the $\mu$-holes, the effect of radial diffusion becomes more dominant at the edges compared to the linear diffusion within the recession. The resultant deposit shows more Pt nanoparticles at the edges rather than at the center of the $\mu$-holes, growing into 3D cauliflowers with an essentially hollow core. Gaps in-between the cauliflower buds correspond with 
electrodes adjacent in the array, i.e. more Pt is deposited at the primary overlapping diffusion zones (see Fig. S1, supporting information).

Fig. 3d shows the image of 'cauliflower B' MATFE with an inset of a close-up of one 3D cauliflower. The average diameter of 'cauliflower B' deposits were found to be slightly larger $(22 \pm 1 \mu \mathrm{m})$ than 'cauliflower A' due to the faster rate of mass transfer and more material is deposited. Fig. 4 shows the AFM 3D images of one representative microhole of the Pt-deposited MATFEs, along with depth and height profiles for recessed, filled and 3D cauliflower shaped deposits. There was some variation in the shapes of the deposits between each microhole (e.g the number of individual buds was different), but the average height and diameter was quite similar between holes on the same array.

Fig. 5 shows magnified SEM images for a single $\mu$-hole on the same modified surfaces. For the filled hole (Fig. 5b), the distribution of nanoparticles shows a relatively uniform filling in the $\mu$-hole and the deposit appears to be fully contained within the $\mu$-hole, with a greater density of nanoparticles near the edges. In the case of 'cauliflower A' and 'cauliflower B' MATFEs (Fig. 5c and Fig. 5d), the filled $\mu$ holes can be seen very clearly with aggregated nanoparticles at the center of the cauliflowers. On the edges of the $\mu$-holes, the Pt-deposits grow at a faster rate, due to the dominance of radial diffusion at the edges of the $\mu$-holes. The number of individual cauliflower segments appears to be larger on 'cauliflower B' MATFE than 'cauliflower A' MATFE due to the faster rate of mass transfer, resulting in larger sized 3D cauliflower shaped Pt nanostructures. Fine structure of the nanoparticles can be observed on each individual bud (see close-up image in the supporting information, Fig. S2).

Over the whole array of 90 electrodes on the filled MATFE, a relatively uniform distribution of 2D Pt nanostructures is seen, but with slightly less deposit within the $\mu$-holes situated in the corner positions (see SEM image in Fig. S1b, supporting information). This pattern is similar for the 'cauliflower A' and 'cauliflower B' MATFEs, where the deposits on the corner $\mu$-holes are not as large or regular in shape compared to those near the center (see Fig. S1c and Fig. S1d). This could be due to the different amounts of flux affecting the $\mu$-holes at the edges, compared to those near the center where the diffusion layers are overlapping $[51,52]$ on the long timescale of the deposition (300 seconds).

\subsection{Electrochemical Oxidation of Ammonia on Pt 2D Nanostructured and 3D Cauliflower Microarrays.}

The four electrode surfaces described above were employed as working electrodes for the oxidation of ammonia gas. The room temperature ionic liquid (RTIL) $\left[\mathrm{C}_{2} \mathrm{mim}\right]\left[\mathrm{NTf}_{2}\right]$ was used as the electrolyte due to its wide electrochemical window $(>4.5 \mathrm{~V})$, good chemical and thermal stability, high ionic conductivity, its relatively low viscosity compared to other available RTILs and good electrochemical response for ammonia oxidation $[53,54]$. The filled MATFE has already demonstrated to give enhanced 
currents for ammonia oxidation in ionic liquids compared to the recessed MATFE in our previous work [33]; the novel cauliflower structures are expected to provide significant further enhancement.

Prior to studying the analytical response on these modified microarrays, cyclic voltammetry (CV) was first performed to study the mechanism. The ammonia oxidation mechanism in ionic liquids on conventional electrodes shows a single, broad oxidation peak corresponding to the oxidation of ammonia to nitrogen and protons, the latter of which is solvated by the anion $\left(\mathrm{A}^{-}\right)$of the ionic liquid $[54,55]$ :

$$
\mathrm{NH}_{3}(\mathrm{~g})+3 \mathrm{~A}^{-} \rightarrow \frac{1}{2} \mathrm{~N}_{2}(\mathrm{~g})+3 \mathrm{HA}+3 \mathrm{e}^{-}
$$

where $\mathrm{A}^{-}$in this case is $\left[\mathrm{NTf}_{2}\right]^{-}$, and HA is the solvated proton. On the reverse scan, two reduction peaks are typically observed, corresponding to the reduction of the solvated proton and the reduction of the ammonium ion, respectively $[54,55]$. An additional oxidation peak corresponds to the oxidation of adsorbed hydrogen. The cyclic voltammograms on all four microarray surfaces show the presence of these four redox peaks (see Fig. S4 in the supporting information), suggesting that the mechanism is the same as reported previously $[54,55]$. A slight increase in current response for ammonia oxidation can be seen from the non-modified to the filled MATFEs, due to the improved radial diffusion as a result of filling the $\mu$-holes. However, a dominant increase (four to seven times) can be seen when the $\mu$-holes are filled and decorated with 3D cauliflower like nanostructures. The response shows a slanted steady-state shape on the MATFE, consistent with that observed previously [33]. 'Cauliflower B' MATFE shows a more flat current response, indicating a possible overlap in diffusion profiles due to the larger $3 \mathrm{D}$ cauliflower deposits.

Table 1 shows a comparison of the oxidation peak current, $I_{\mathrm{p}}$, for $500 \mathrm{ppm}$ ammonia on all these surfaces. The raw peak current increased by almost an order of magnitude from the recessed MATFE (16 $\mathrm{nA})$ to the 'cauliflower B' MATFE (110 nA), demonstrating improved response to ammonia. Further characterisation was thus performed to determine sensitivity, and whether such enhancements are related to larger electrodes or enhanced flux.

\subsection{Comparison of Current Density.}

In order to compare the oxidation of ammonia on the different microarrays, and to normalize for different electrode areas, the current density $(J)$ was calculated from the steady-state oxidation current divided by the electroactive surface area (ESA). The ESA of the Pt on the modified/unmodified arrays was quantified using the classical hydrogen adsorption features observed for $\mathrm{Pt}$ in acidic aqueous media. Cyclic voltammetry $(\mathrm{CV})$ in a $\mathrm{N}_{2}$ saturated solution of $0.5 \mathrm{M} \mathrm{H}_{2} \mathrm{SO}_{4}$ was performed between -0.27 and $+1.4 \mathrm{~V}$ at a scan rate of $500 \mathrm{mVs}^{-1}$ (see Fig. 6a). The inset to Fig. 6a shows a close-up view of the hydrogen atom desorption peaks (background subtracted) - the different shapes could indicate the presence of different crystal faces on the Pt deposit. The ESA can be calculated using standard methods $[41,42]$ according to the following equation: 


$$
\operatorname{ESA}\left(\mathrm{cm}^{2}\right)=\frac{Q_{\mathrm{H}}}{210 \mu \mathrm{C} \mathrm{cm^{-2 }}}
$$

where $Q_{\mathrm{H}}$ is the charge calculated by integrating the hydrogen adsorption/desorption peaks from $-0.2 \mathrm{~V}$ to $0.2 \mathrm{~V}$, and is given by [41]:

$$
Q_{\mathrm{H}}=I \times t
$$

where $I=$ current and $t=$ time. As the surface area increased, the adsorption and desorption peaks became sharper and more defined. This could correspond to gradually changing crystalline facets of Pt, but could equally refer to dynamics in the solution concentration at the highly structured surfaces.

The determined ESA values (Table 1) demonstrated a modest ( $c$. 2-fold) enhancement in the ESA of Pt upon going from the recessed MATFE to the 'cauliflower B' MATFE. This clearly indicates that enhanced flux was primarily responsible for the $c a$. 10-fold enhancement in current.

Fig. $6 \mathrm{~b}$ shows the current density $\left(J ; \mathrm{I}_{\mathrm{p}} / \mathrm{ESA}\right)$ plot for $500 \mathrm{ppm}$ ammonia oxidation on the four MATFEs in $\left[\mathrm{C}_{2} \mathrm{mim}\right]\left[\mathrm{NTf}_{2}\right]$. This plot shows two regimes: a slight increase in $J$ from recessed to filled MATFEs, due to the improved characteristics of radial diffusion as a result of filling of $\mu$-holes. Next, a significant increase in $J$ can be seen from the filled MATFE to 'cauliflower B' MATFE. This is due to enhanced flux via multidimensional radial diffusion towards the 3D cauliflower shaped nanostructures. Based on these observations, the Pt-deposited MATFEs were employed for further analytical experiments, to investigate whether these modified MATFEs can be used to improve the sensitivity for low concentration detection of ammonia in RTILs.

\subsection{Analytical Response for Ammonia Oxidation on Pt 2D and 3D Decorated Microarrays.}

In order to investigate the ability of the Pt-deposited MATFEs to detect ammonia, the analytical utility and sensitivity for ammonia in $\left[\mathrm{C}_{2} \mathrm{mim}\right]\left[\mathrm{NTf}_{2}\right]$ was studied and compared. For this, linear sweep voltammetry was employed for ammonia oxidation at different concentrations. Potential step chronoamperometry (PSCA) was also employed on the recessed and Pt-deposited 3D cauliflower decorated MATFEs to test the ability of the modified microarrays for "real-time" analyte detection, also allowing the calculation of response times.

\subsubsection{Linear Sweep Voltammetry.}

Fig. 7 shows linear sweep voltammetry (LSV) for the oxidation of 10-100 ppm ammonia in $\left[\mathrm{C}_{2} \mathrm{mim}\right]\left[\mathrm{NTf}_{2}\right]$ on all four surfaces at a scan rate of $100 \mathrm{mV} / \mathrm{s}$. The red dashed line is the response in the absence of ammonia. A slanted steady-state response is observed for all electrodes, with current measured at a fixed potential increasing linearly with concentration. An increase in the background current is also noted for the cauliflower structures due to the increased surface area, but this does not appear to affect the sensing response, since this background is easily subtracted. Oxidation peak currents were measured from a fixed potential and plotted against the respective concentration, shown in the insets to Fig. 7. Excellent 
linearity $\left(\mathrm{R}^{2}>0.999\right)$ was obtained on all Pt-deposited MATFEs for the concentration range studied. The current response was highly reproducible on freshly prepared electrodes $(n=3)$, and also on the same electrode used for several days ( $n=5$, with sulfuric acid activation performed between experiments), with error bars (1 standard deviation) that were $<5 \%$ on all surfaces. Fig. 8 shows the absolute current $v s$ different concentrations of ammonia (10-100 ppm) plotted together for the recessed and Pt-modified MATFEs. The gradient for the recessed MATFE is the smallest, while the filled MATFE is slightly higher due to the reduction in the recession depth as a result of filling of the $\mu$-holes. However, the gradients for the 'cauliflower A' and 'cauliflower B' MATFEs are greatly increased due to the increased surface area and the enhanced radial diffusion towards the 3D nanostructures.

Table 1 shows sensitivity values $\left(\mathrm{A} \mathrm{ppm}^{-1}\right.$ ) and limit of detection (LOD) values, which were obtained from the calibration plots in Fig. 8. The sensitivity values were calculated from the gradient of the line of best-fit and LODs were obtained using three times standard deviation of the line of best fit. The sensitivity of the filled MATFE is higher than the recessed MATFE (enhanced by 42\%). However, when the $\mu$-holes are completely filled and decorated with 3D cauliflower shaped deposits, the sensitivity values are 4.5 times higher for 'cauliflower A' and 6.5 times higher for 'cauliflower B' compared to the recessed MATFEs. The LOD values calculated for the 10-100 ppm ammonia concentration range on recessed and all Pt-deposited MATFEs were much lower (0.8 to $2 \mathrm{ppm}$ ) than the permissible exposure limit (PEL) of $25 \mathrm{ppm}$ in the gas phase [34]. Importantly, LODs are the lowest for the two cauliflower deposits, showing enhanced sensitivity due to a higher electroactive surface area and 3D shaped deposits. The LODs could be further improved if a lower concentration range is studied, as demonstrated previously [33], but this is not the focus of present work - the aim here is to improve the sensitivity of the surface at environmentally relevant ammonia concentrations; this single step modification has demonstrated a 6.5-fold increase in sensitivity. These observations suggest that $\mu$-holes filled with 3D cauliflower shaped nanostructures can be employed to enhance detection of a wide range of potential gaseous analytes in RTILs, at very high sensitivity values and thus down to very low concentrations. Importantly, this will significantly facilitate analysis of more toxic gases, with sub-ppm PEL values.

\subsubsection{Potential Step Chronoamperometry.}

In order to test the ability of 3D cauliflower decorated MATFEs $v s$ recessed MATFEs for "real-time" detection of ammonia in RTILs and to calculate response time, potential step chronoamperometry (PSCA) was performed. Fig. 9 shows the current response for $10 \mathrm{ppm}$ ammonia on both recessed and 'cauliflower B' MATFE in $\left[\mathrm{C}_{2} \mathrm{mim}\right]\left[\mathrm{NTf}_{2}\right]$. The maximum current obtained on 'cauliflower B' MATFE was ca. twelve times higher than for the recessed MATFE indicating the huge enhancement in response with the 3D deposit using this method. 
The response time was calculated from $90 \%$ of the maximum current [56]. For the recessed MATFE, the response time was ca. $315 \pm 20$ seconds while on 'cauliflower B' MATFE, it was ca. $200 \pm$ 15 seconds. These times are relatively long, due to the thickness of the RTIL layer (estimated to be $0.14 \pm$ $0.03 \mathrm{~mm}$ using a volume of $\left.2 \mu \mathrm{L}\left[\mathrm{C}_{2} \mathrm{mim}\right]\left[\mathrm{NTf}_{2}\right]\right)$. A decrease after the maximum current, rather than a plateau, was observed on both the recessed and 'cauliflower B' MATFE. This could be due to some degree of fouling of the surface due to a build-up of electrogenerated products over the long timescale of the chronoamperometry experiment, as reported in the literature [57]. This would not be an issue for the detection of gases that are not omnipresent in the atmosphere, e.g. chemical warfare agents.

\section{Conclusions}

Repeating arrays of unique cauliflower-shaped $\mathrm{Pt}$ deposits have been synthesised in a single electrochemical step using the walls of recessed microelectrode arrays to support and template their growth. Due to the dominance of radial diffusion at the edges of the walls and linear diffusion at the centre in the recession, a larger deposit is seen over the edges of the $\mu$-holes; precisely where they need to be for sensitive responses to dissolved analytes. SEM and AFM characterisation revealed the sizes and shapes of the structures, with the largest cauliflower structures produced when using: a higher concentration of $\mathrm{Pt}$ precursor, a higher potential, and stirring of the solution. The modified and unmodified MATFEs were employed for ammonia oxidation in an ionic liquid. Current responses were ca. seven times higher for LSV, and 12 times higher for PSCA, on microarrays decorated with cauliflower structures compared to the recessed microarrays. Calibration plots from 10-100 ppm ammonia were linear, with the highest sensitivities and lowest LODs $(0.8 \mathrm{ppm})$ found on cauliflower decorated MATFEs. These results suggest that low-cost miniaturised electrodes can be easily modified with 3D Ptcauliflower shaped nanostructures in a single step to produce enhanced detection of analytes such as ammonia in ionic liquids.

\section{Supporting Information/Appendix}

SEM image of seven microholes on 'cauliflower B' MATFE showing the direction of overlapping diffusion fields towards the adjacent microholes, a close-up image of the fine structures on the cauliflower buds, SEM image of all 90 microholes (for the recessed, filled, 'cauliflower A' and 'cauliflower B' MATFEs), and cyclic voltammetry for 500 ppm ammonia oxidation on all four surfaces.)

\section{Acknowledgements}

GH thanks Curtin University, the Department of Chemistry and the Curtin Institute for Functional Molecules and Interfaces (CIFMI) for a PhD scholarship. This work was supported by an Australian Research Council (ARC) Discovery grant (DP150101708) and an ARC Discovery Early Career Research 
Award (DE120101256) for DSS. The authors acknowledge the use of equipment of the Curtin University Electron Microscope Facility, which is partially funded by the University, State and Commonwealth Governments of Australia, and the use of the instruments of the Scanning Probe Microscopy facility of the CIFMI/Department of Chemistry at Curtin University, funded by ARC LIEF grant number LE130100121. The authors also thank Ms Elaine Miller and Dr Thomas Becker for technical assistance of scanning electron microscopy and scanning probe microscopy instruments, respectively.

\section{$\underline{\text { Tables }}$}

Table 1. Analytical parameters obtained: charge $\left(Q_{\mathrm{H}}\right)$, electroactive surface area (ESA) calculated from the integration of $\mathrm{H}_{2}$ desorption peak obtained in $\mathrm{N}_{2}$-saturated $0.5 \mathrm{M} \mathrm{H}_{2} \mathrm{SO}_{4}$ at $500 \mathrm{mVs}^{-1} \mathrm{vs} \mathrm{Ag} / \mathrm{AgCl}$ reference electrode and $\mathrm{Pt}$ counter electrode, oxidation peak current $\left(I_{\mathrm{p}}\right)$ for $500 \mathrm{ppm}$ ammonia, measured at fixed potential $+1.3 \mathrm{~V}$, current density $(J)$ for $500 \mathrm{ppm} \mathrm{NH}_{3}$, sensitivity and limit of detection (LOD) calculated for ammonia oxidation (10-100 ppm) on an unmodified MATFE and all Pt-deposited MATFEs using linear sweep voltammetry.

\begin{tabular}{|l|l|l|l|l|l|l|}
\hline Electrode & $\begin{array}{l}Q_{\mathrm{H}}=I \times t \\
/(\mu \mathrm{C})\end{array}$ & $\begin{array}{l}\text { ESA } \\
/\left(\mathrm{m}^{2}\right)\end{array}$ & $\begin{array}{l}I_{\mathrm{p}} \\
/(\mathrm{A})\end{array}$ & $\begin{array}{l}J \\
/\left(\mathrm{Am}^{-2}\right)\end{array}$ & $\begin{array}{l}\text { Sensitivity } \\
/\left(\mathrm{Appm}^{-1}\right)\end{array}$ & $\begin{array}{l}\text { LOD } \\
/ \mathrm{ppm})\end{array}$ \\
\hline Recessed MATFE & 2.16 & $1.02 \times 10^{-06}$ & $1.6 \times 10^{-08}$ & $1.5 \times 10^{-02}$ & $4.0 \times 10^{-11}$ & 2.0 \\
\hline Filled MATFE & 2.42 & $1.15 \times 10^{-06}$ & $2.0 \times 10^{-08}$ & $1.7 \times 10^{-02}$ & $4.9 \times 10^{-11}$ & 1.3 \\
\hline 'Cauliflower A' & 3.48 & $1.66 \times 10^{-06}$ & $6.7 \times 10^{-08}$ & $4.0 \times 10^{-02}$ & $1.8 \times 10^{-10}$ & 0.8 \\
\hline 'Cauliflower B' & 4.20 & $2.00 \times 10^{-06}$ & $1.1 \times 10^{-07}$ & $5.7 \times 10^{-02}$ & $2.6 \times 10^{-10}$ & 0.8 \\
\hline
\end{tabular}




\section{Figures}

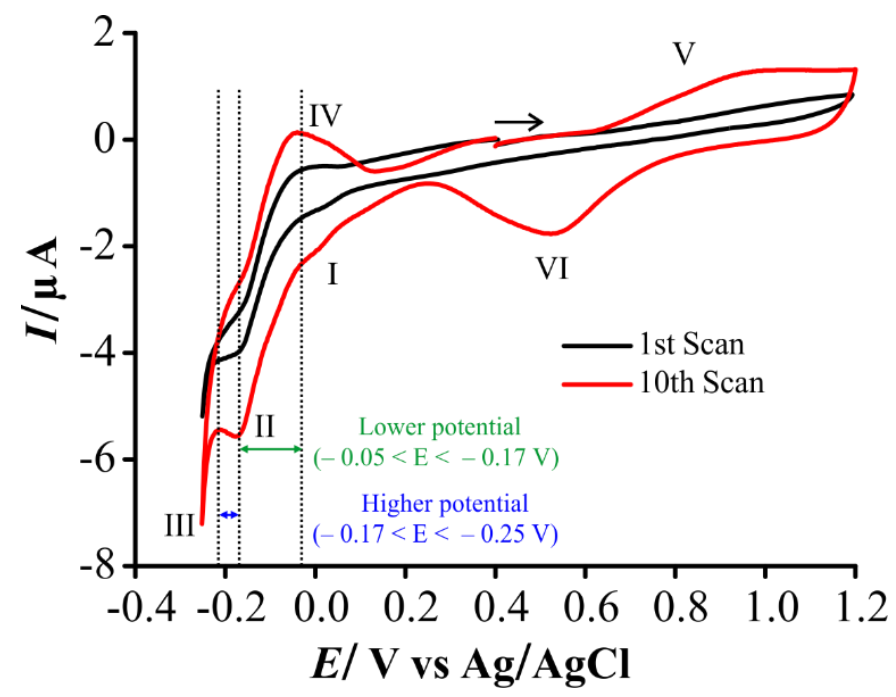

Fig. 1 Cyclic voltammograms recorded on a recessed Pt MATFE (90 electrodes, $10 \mu \mathrm{m}$ in diameter) in a solution of $\mathrm{N}_{2}$-saturated $20 \mathrm{mM} \mathrm{H}_{2} \mathrm{PtCl}_{6}$ in $0.5 \mathrm{M} \mathrm{H}_{2} \mathrm{SO}_{4}$ at $100 \mathrm{mVs}^{-1}$.
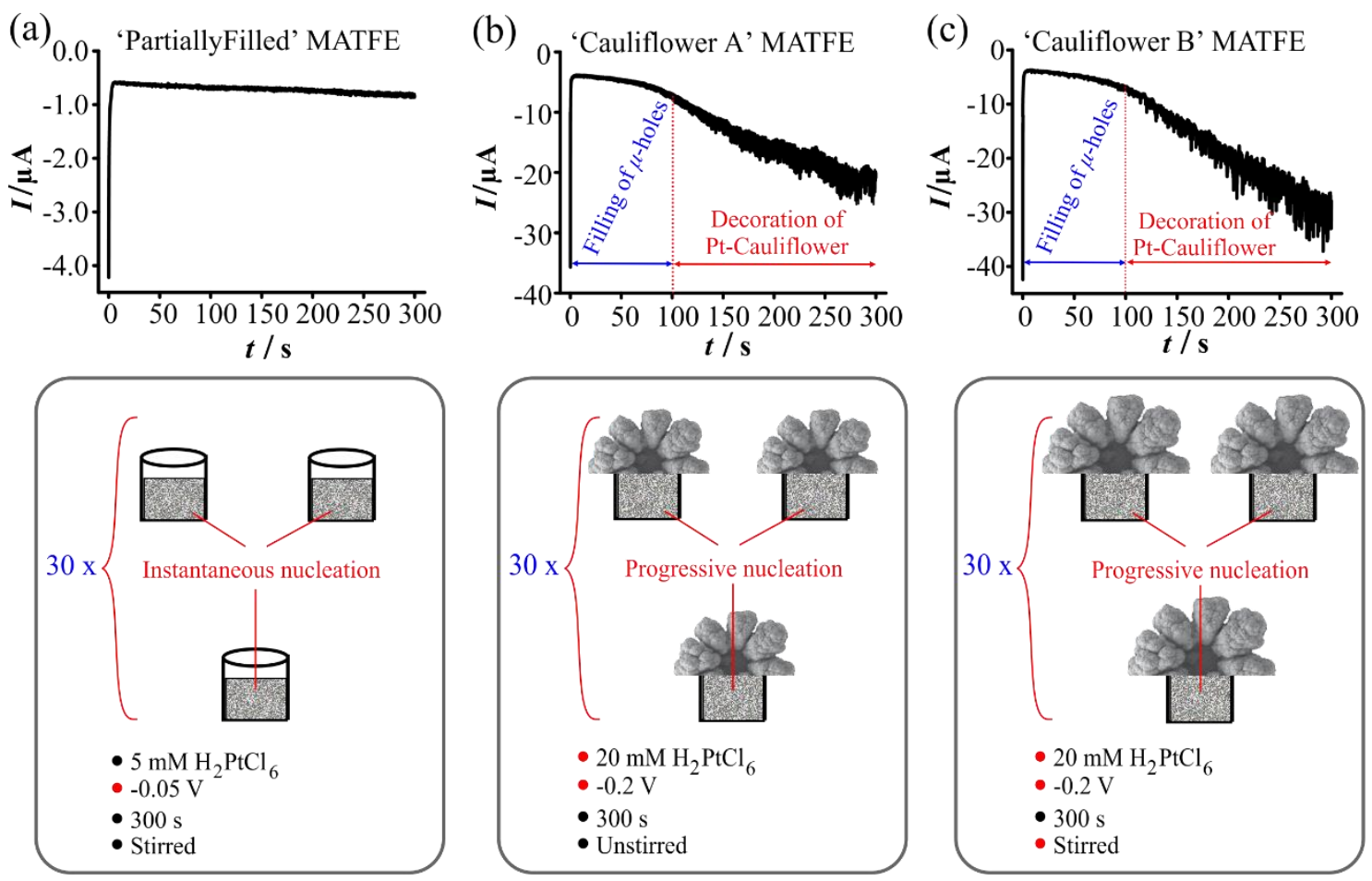

Fig. 2. Chronoamperometric transients for Pt-deposition on Pt recessed MATFEs using a $5 \mathrm{mM}$ or 20 $\mathrm{mM} \mathrm{N}$-saturated $\mathrm{H}_{2} \mathrm{PtCl}_{6}$ in $0.5 \mathrm{M} \mathrm{H}_{2} \mathrm{SO}_{4}$. The potential was stepped from $0.75 \mathrm{~V}$ (OCP) to (a) $-0.05 \mathrm{~V}$ for filled MATFE, (b) $-0.2 \mathrm{~V}$ for 'cauliflower A' MATFE, and (c) -0.2 for 'cauliflower B' MATFE. The cartoons below show the expected filling of the recessed pores and the electrochemical parameters employed for the deposition. 

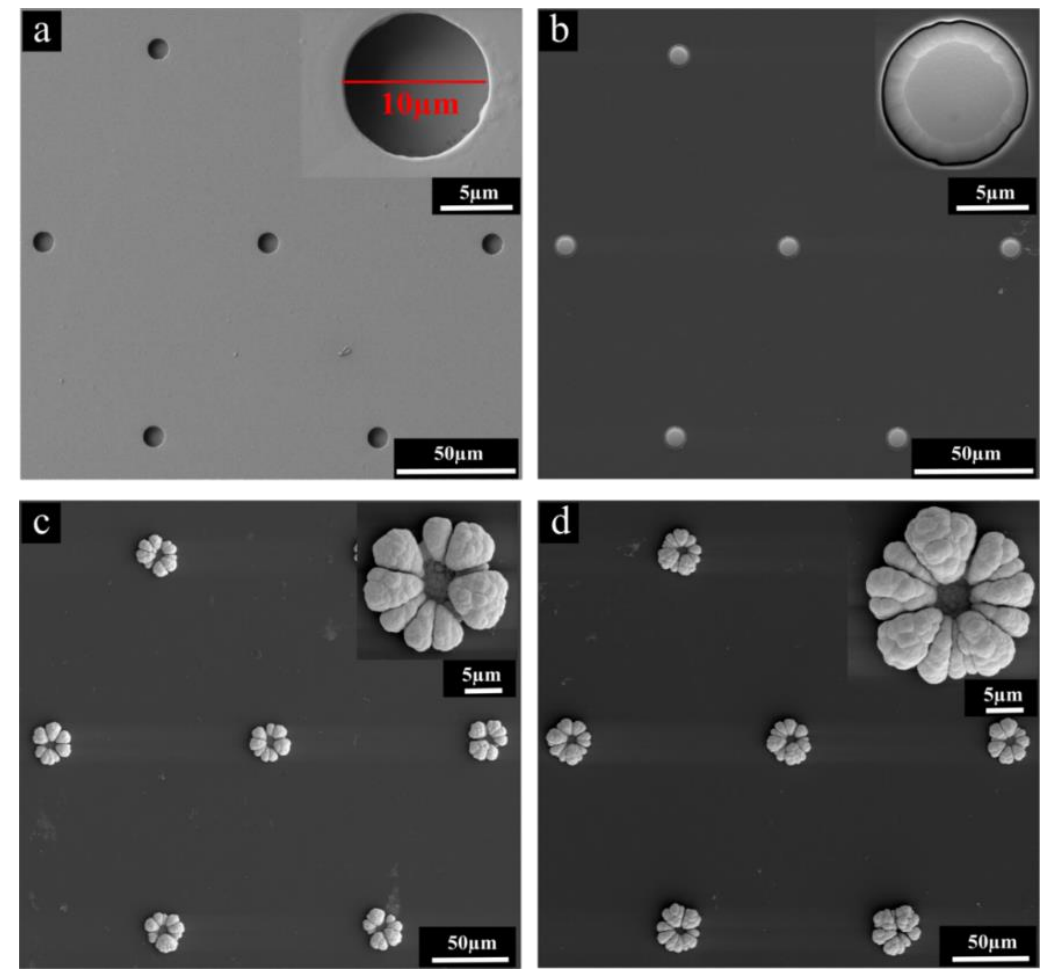

Fig 3. Scanning electron microscopy (SEM) images of recessed, $2 \mathrm{D}$ and 3D Pt-modified MATFEs (a) recessed MATFE (90 recessed electrodes, diameter $10 \mu \mathrm{m}$, depth $2.8 \mu \mathrm{m}$ ), (b) filled MATFE (depth $0.9 \pm 0.05 \mu \mathrm{m}$ ), (c) 'cauliflower A' MATFE (diameter of cauliflower $18 \pm 0.5 \mu \mathrm{m}$ ), and (d) 'cauliflower B' MATFE, (diameter of cauliflower $22 \pm 1 \mu \mathrm{m}$ ). Error bars represent one standard deviation of seven deposits on the same array.
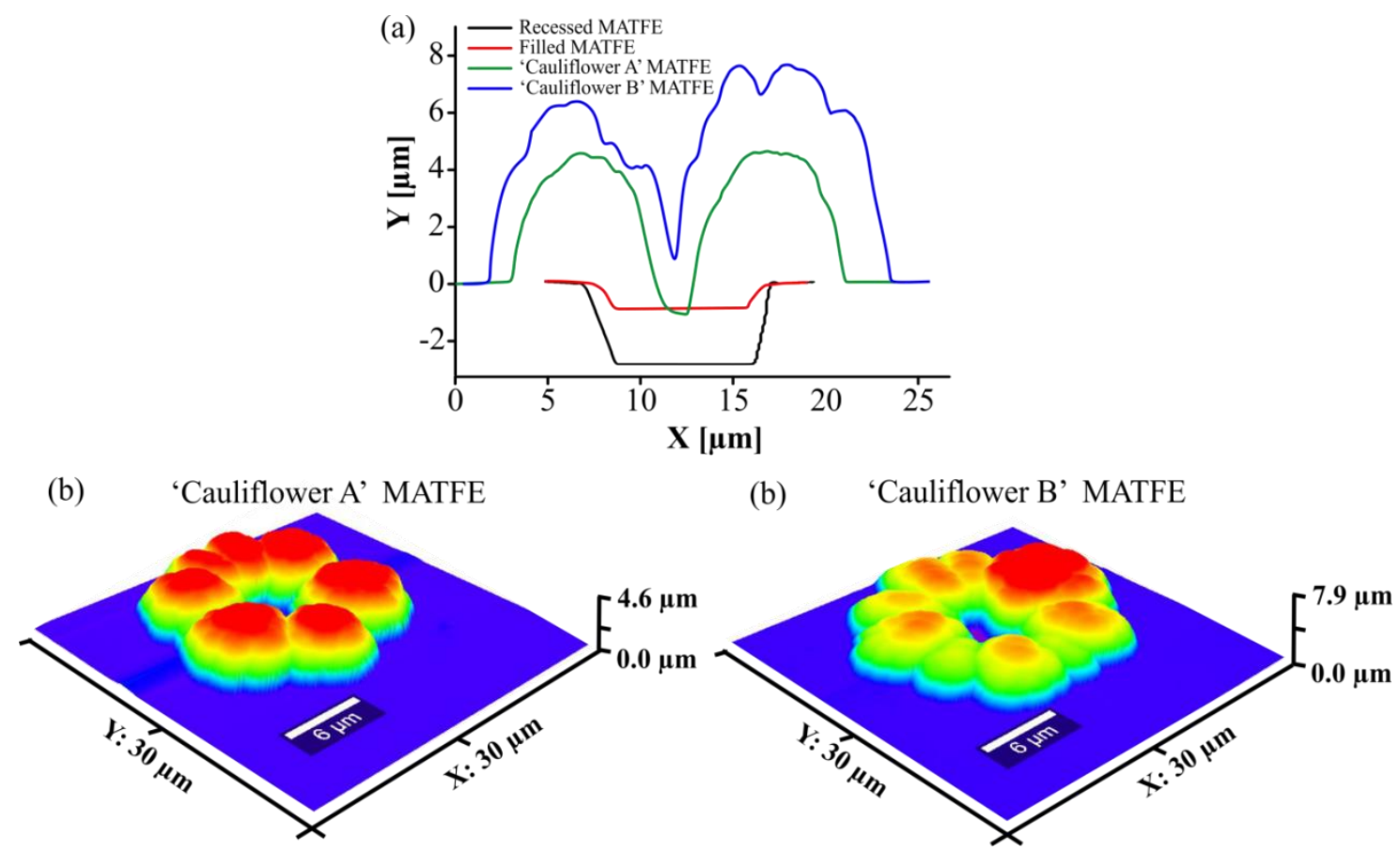

Fig 4. (a) Depth and height profiles of recessed, 2D, and 3D Pt-modified MATFEs. Atomic force microscopy (AFM) 3D images of a single microhole of (b) 'cauliflower A' MATFE (diameter of cauliflower $18 \pm 0.5 \mu \mathrm{m}$, height $=4.6 \pm 0.2 \mu \mathrm{m}$, depth $=1.1 \pm 0.02 \mu \mathrm{m}$ ), (c) 'cauliflower B' MATFE, (diameter of cauliflower $22 \pm 0.3 \mu \mathrm{m}$, height $=7.9 \pm 0.2 \mu \mathrm{m}$, depth $=0.6 \pm 0.02 \mu \mathrm{m}$ ). Error bars represent one standard deviation of seven deposits on the same array. 

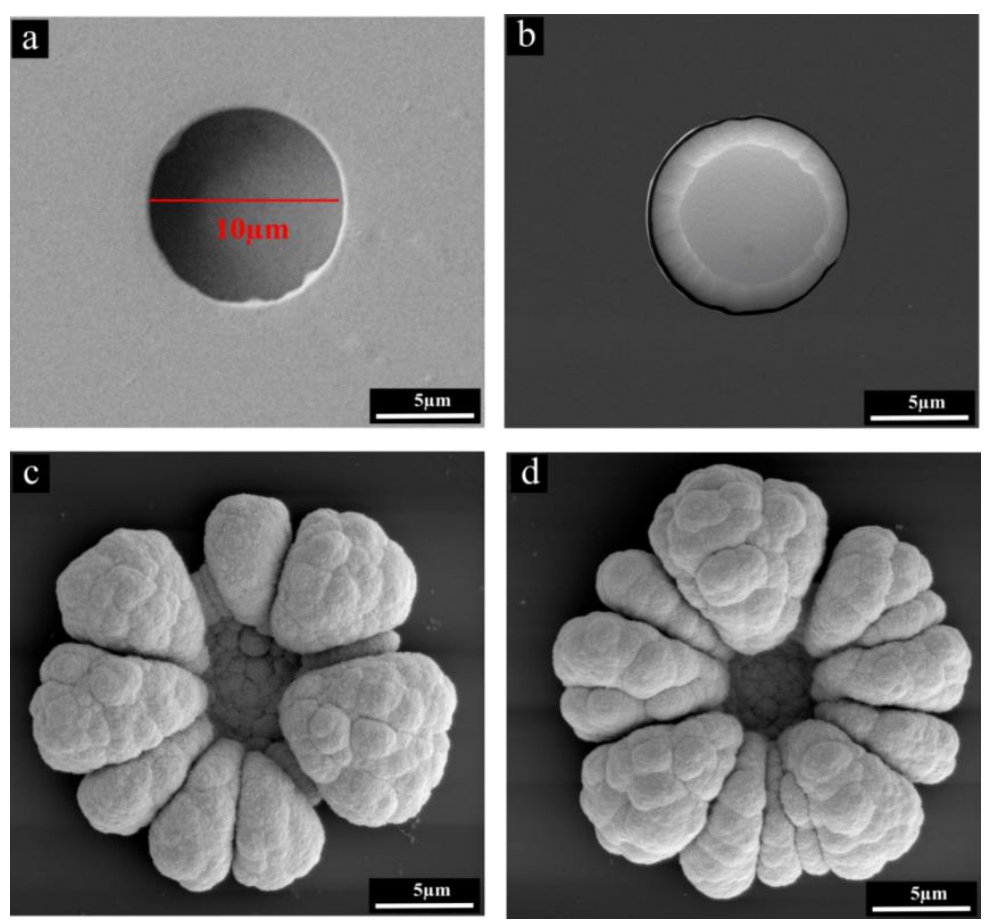

Fig. 5. Scanning electron microscopy (SEM) images of a single microhole showing Pt deposits on MATFEs: (a) recessed MATFE (b) filled MATFE, (c) 'cauliflower A' MATFE, and (d) 'cauliflower B' MATFE.
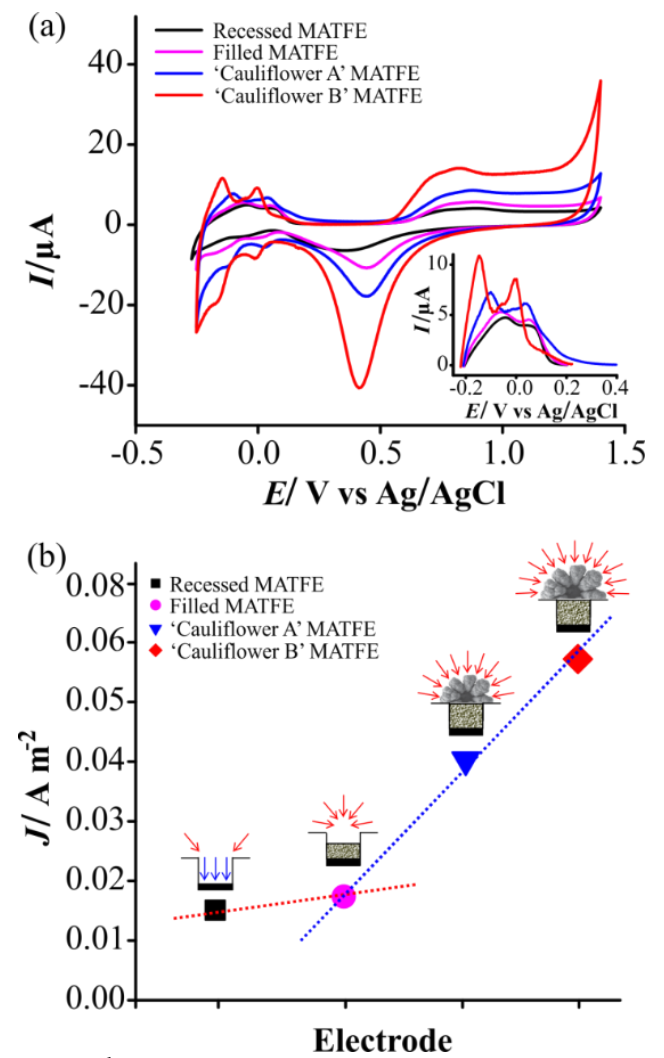

Fig. 6. (a) Cyclic voltammograms $\left(10^{\text {th }}\right.$ cycle $)$ recorded on the four MATFEs between $+1.4 \mathrm{~V}$ and $-0.27 \mathrm{~V}$ in a $\mathrm{N}_{2}$-saturated solution of $0.5 \mathrm{M} \mathrm{H}_{2} \mathrm{SO}_{4}$ at $500 \mathrm{mVs}^{-1}$. The inset shows the $\mathrm{H}_{2}$ desorption peaks (background subtracted) whose integrated area $(Q=I \times t)$ is used to calculate the electrochemical surface area (ESA). (b) Current density $(J)$ plot for the oxidation of $500 \mathrm{ppm}$ ammonia in $\left[\mathrm{C}_{2} \mathrm{mim}\right]\left[\mathrm{NTf}_{2}\right]$ on a Pt: recessed MATFE ( $\boldsymbol{\bullet})$, filled MATFE $(\bullet)$, 'cauliflower A' MATFE $(\boldsymbol{\nabla})$ and 'cauliflower B' MATFE $(\bullet)$ ). Sketches of the expected diffusion processes (radial and linear combined, and radial) based on the electrode geometry are also shown. 

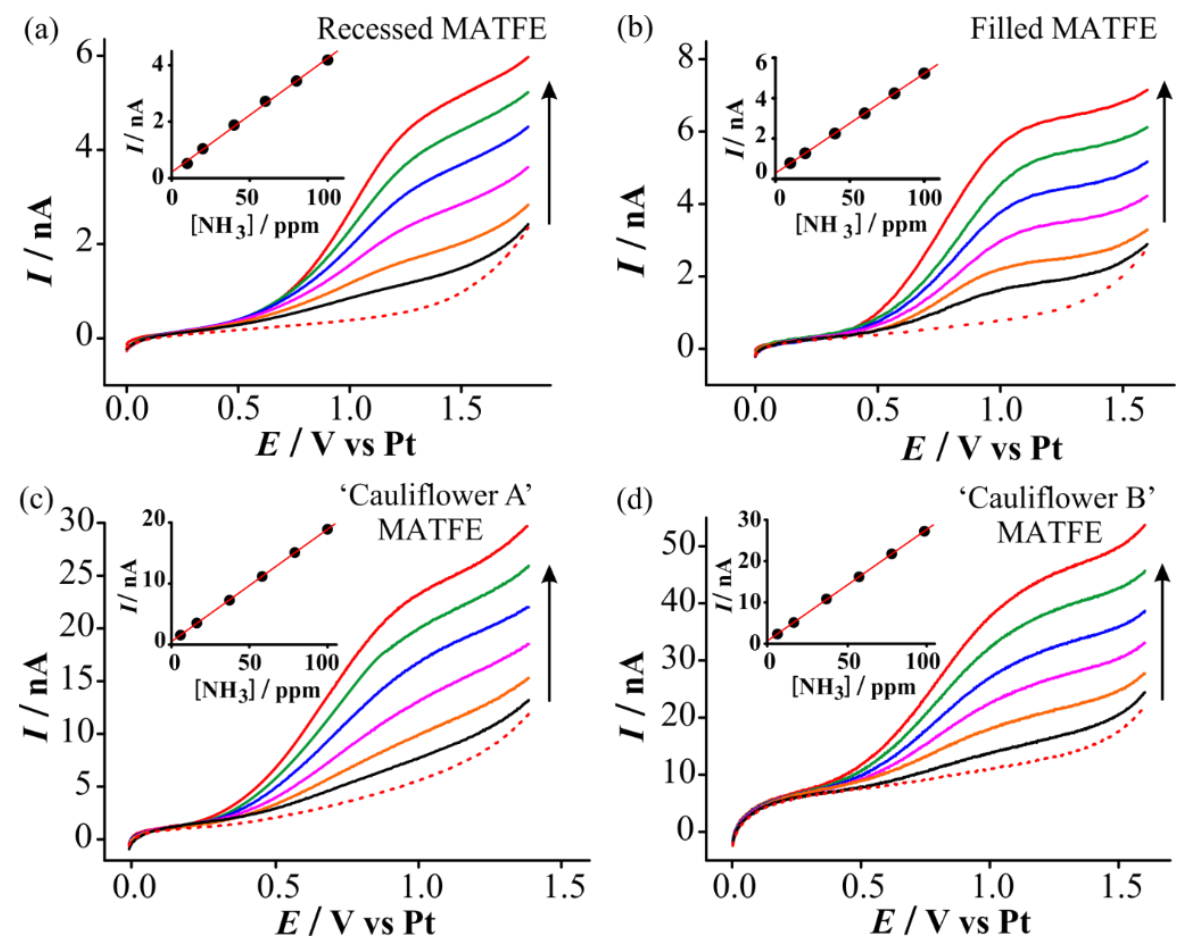

Fig 7. Linear sweep voltammetry (LSV) for the oxidation of ammonia (10-100 ppm) in $\left[\mathrm{C}_{2} \mathrm{mim}\right]\left[\mathrm{NTf}_{2}\right]$ on a Pt (a) recessed MATFE, (b) filled MATFE, (c) 'cauliflower A' MATFE, (d) 'cauliflower B' MATFE at a scan rate of $100 \mathrm{mVs}^{-1}$. Dotted line is the response in the absence of ammonia. Currents on all MATFE were measured from a fixed potential of 1.5, 1.3, 1.2 and $1.3 \mathrm{~V}$, respectively. The insets show the calibration plots of peak current (baseline corrected) vs concentration, along with the line of best fit.

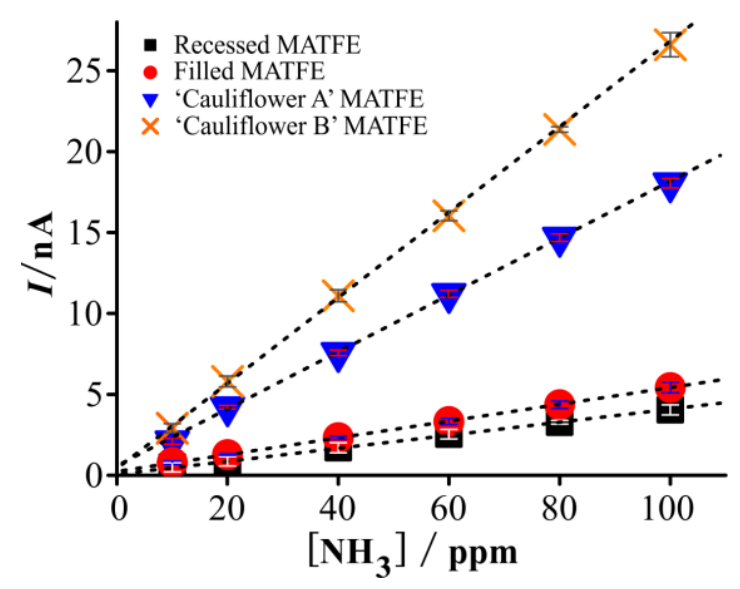

Fig 8. Plot of absolute current $v s$ ammonia concentration for the oxidation of 10-100 ppm ammonia in $\left[\mathrm{C}_{2} \mathrm{mim}\right]\left[\mathrm{NTf}_{2}\right]$ on a Pt: recessed MATFE ( $\left.\mathbf{\square}\right)$, filled MATFE $(\bullet)$, 'cauliflower A' MATFE $(\boldsymbol{\nabla})$ and 'cauliflower B' MATFE $(\times)$. Error bars represent one standard deviation of three repeat scans on the same electrode. 


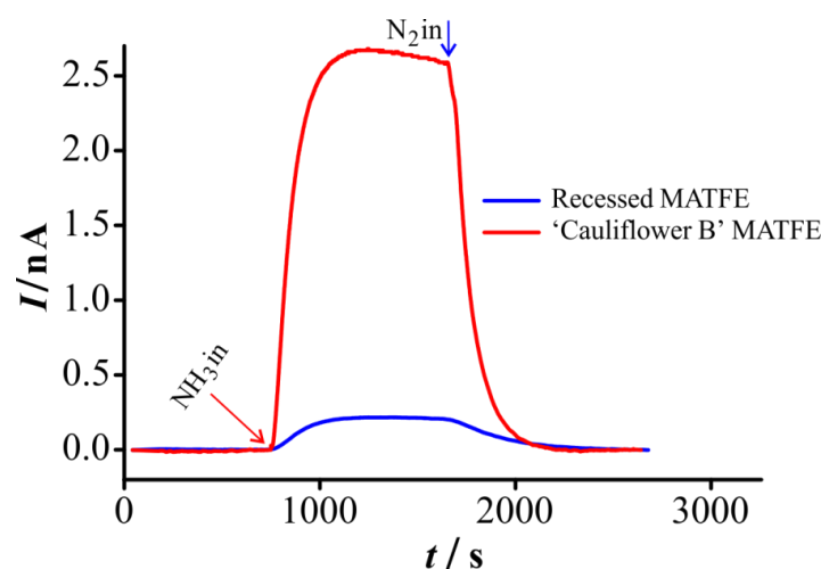

Fig 9. Potential step chronoamperometry (PSCA) for $10 \mathrm{ppm}$ ammonia oxidation on recessed and 'cauliflower B' MATFEs in the RTIL $\left[\mathrm{C}_{2} \mathrm{mim}\right]\left[\mathrm{NTf}_{2}\right]$. The potential was stepped from 0 to $+1.3 \mathrm{~V}$ vs. Pt. The arrows correspond to the introduction of $10 \mathrm{ppm}$ ammonia gas, then pure nitrogen gas. 


\section{References}

[1] J.R. Stetter, J. Li, Amperometric Gas Sensors - A Review, Chem. Rev., 108 (2008) 352-366.

[2] R.B. Swotinsky, K.H. Chase, Health effects of exposure to ammonia: scant information, Am. J. Ind. Med., 17 (1990) 515-521.

[3] L. Xiong, R.G. Compton, Amperometric Gas detection: A Review, Int. J. Electrochem. Sci., 9 (2014) 7152-7181.

[4] M.C. Buzzeo, C. Hardacre, R.G. Compton, Use of Room Temperature Ionic Liquids in Gas Sensor Design, Anal. Chem., 76 (2004) 4583-4588.

[5] E.I. Rogers, A.M. O'Mahony, L. Aldous, R.G. Compton, Amperometric Gas Detection Using Room Temperature Ionic Liquid Solvents, ECS Trans., 33 (2010) 473-502.

[6] D.S. Silvester, Recent advances in the use of ionic liquids for electrochemical sensing, Analyst, 136 (2011) 4871-4882.

[7] A. Rehman, X. Zeng, Methods and approaches of utilizing ionic liquids as gas sensing materials, RSC Adv., 5 (2015) 58371-58392.

[8] L.E. Barrosse-Antle, A.M. Bond, R.G. Compton, A.M. O 'Mahony, E.I. Rogers, D.S. Silvester, Voltammetry in Room Temperature Ionic Liquids: Comparisons and Contrasts with Conventional Electrochemical Solvents, Chem. Asian J., 5 (2010) 202-230.

[9] F. Wang, S. Hu, Electrochemical Sensors Based on Metal and Semiconductor Nanoparticles, Microchim. Acta, 165 (2009) 1-22.

[10] L. Rassaei, F. Marken, M. Sillanpää, M. Amiri, C.M. Cirtiu, M. Sillanpää, Nanoparticles in Electrochemical Sensors for Environmental Monitoring, Trends Anal. Chem., 30 (2011) 1704-1715.

[11] A.P. O'Mullane, S.J. Ippolito, Y.M. Sabri, V. Bansal, S.K. Bhargava, Premonolayer Oxidation of Nanostructured Gold: An Important Factor Influencing Electrocatalytic Activity, Langmuir, 25 (2009) 3845-3852.

[12] M. Trojanowicz, Analytical Applications of Carbon Nanotubes: A Review, Trends Anal. Chem., 25 (2006) 480-489.

[13] U. Yogeswaran, S.-M. Chen, A Review on the Electrochemical Sensors and Biosensors Composed of Nanowires as Sensing Material, Sensors, 8 (2008) 290-313.

[14] L.C. Tien, P.W. Sadik, D.P. Norton, L.F. Voss, S.J. Pearton, H.T. Wang, B.S. Kang, F. Ren, J. Jun, J. Lin, Hydrogen Sensing at Room Temperature with Pt-coated ZnO Thin Films and Nanorods, Appl. Phys. Lett., 87 (2005) 222106.

[15] B.J. Plowman, A.P. O'Mullane, P.R. Selvakannan, S.K. Bhargava, Honeycomb nanogold networks with highly active sites, Chem. Commun., 46 (2010) 9182-9184.

[16] Y. Yamauchi, A. Tonegawa, M. Komatsu, H. Wang, L. Wang, Y. Nemoto, N. Suzuki, K. Kuroda, Electrochemical Synthesis of Mesoporous Pt-Au Binary Alloys with Tunable Compositions for Enhancement of Electrochemical Performance, J. Am. Chem. Soc., 134 (2012) 5100-5109.

[17] N. Zhang, K. Yu, Q. Li, Z.Q. Zhu, Q. Wan, Room-Temperature High-Sensitivity H2S Gas Sensor Based on Dendritic ZnO Nanostructures with Macroscale in Appearance, J. Appl. Phys., 103 (2008) 104305.

[18] A.K. Pearson, P. Kao, A.P. O'Mullane, A.I. Bhatt, Investigating the effect of ionic strength on the suppression of dendrite formation during metal electrodeposition, Phys. Chem. Chem. Phys., 19 (2017) $14745-14760$.

[19] C. Kong, S. Sun, J. Zhang, H. Zhao, X. Song, Z. Yang, Nanocube-Aggregated Cauliflower-like Copper Hierarchical Architectures: Synthesis, Growth Mechanism and Electrocatalytic Activity, CrystEngComm, 14 (2012) 5737-5740. 
[20] B.J. Plowman, S.K. Bhargava, A.P. O'Mullane, Electrochemical fabrication of metallic nanostructured electrodes for electroanalytical applications, Analyst, 136 (2011) 5107-5119.

[21] F. Ren, S.J. Pearton, Semiconductor-Based Sensors, World Scientific2016.

[22] B. Zhang, L. Lu, Q. Hu, F. Huang, Z. Lin, ZnO Nanoflower-Based Photoelectrochemical DNAzyme Sensor for the Detection of Pb2+, Biosens. Bioelectron., 56 (2014) 243-249.

[23] R.K. Sonker, S.R. Sabhajeet, S. Singh, B.C. Yadav, Synthesis of ZnO Nanopetals and its Application as NO2 Gas Sensor, Mater. Lett., 152 (2015) 189-191.

[24] H. Zhang, R. Wu, Z. Chen, G. Liu, Z. Zhang, Z. Jiao, Self-Assembly Fabrication of 3D Flower-Like ZnO Hierarchical Nanostructures and their Gas Sensing Properties, CrystEngComm, 14 (2012) 1775-1782.

[25] S. Sun, X. Zhang, Y. Sun, J. Zhang, S. Yang, X. Song, Z. Yang, A Facile Strategy for the Synthesis of Hierarchical CuO Nanourchins and their Application as Non-Enzymatic Glucose Sensors, RSC Adv., 3 (2013) 13712-13719.

[26] X. Zhang, J. Jiang, W. Shi, Three-Dimensional Hierarchical ZnO Nanostructures with Controllable Building Units: Hydrothermal Synthesis, Growth Process and Photocatalytic Activities for Organic Dyes, Micro Nano Lett., 9 (2014) 509-513.

[27] A. Chen, X. Peng, K. Koczkur, B. Miller, Super-Hydrophobic Tin Oxide Nanoflowers, Chem. Commun., (2004) 1964-1965.

[28] M.R. Hormozi Nezhad, M. Aizawa, L.A. Porter, A.E. Ribbe, J.M. Buriak, Synthesis and Patterning of Gold Nanostructures on InP and GaAs via Galvanic Displacement, Small, 1 (2005) 1076-1081.

[29] R.S. Jayashree, J.S. Spendelow, J. Yeom, C. Rastogi, M.A. Shannon, P.J.A. Kenis, Characterization and application of Electrodeposited Pt, Pt/Pd, and Pd Catalyst Structures for Direct Formic Acid Micro Fuel Cells, Electrochim. Acta, 50 (2005) 4674-4682.

[30] J.N. Tiwari, R.N. Tiwari, K.-L. Lin, Synthesis of Pt Nanopetals on Highly Ordered Silicon Nanocones for Enhanced Methanol Electrooxidation Activity, ACS Appl. Mater. Interfaces, 2 (2010) 2231-2237.

[31] A.R. Tao, S. Habas, P. Yang, Shape Control of Colloidal Metal Nanocrystals, Small, 4 (2008) 310-325.

[32] T.K. Sau, A.L. Rogach, Nonspherical Noble Metal Nanoparticles: Colloid-Chemical Synthesis and Morphology Control, Adv. Mater., 22 (2010) 1781-1804.

[33] G. Hussain, D.S. Silvester, Detection of sub-ppm Concentrations of Ammonia in an Ionic Liquid: Enhanced Current Density Using "Filled" Recessed Microarrays, Anal. Chem., 88 (2016) 12453-12460.

[34] K.J. Donham, P.S. Thorne, G.M. Breuer, W. Powers, S. Marquez, S.J. Reynolds, Chapter 8: Exposure Limits Related to Air Quality and Risk Assessment, lowa Concentrated Animal Feeding Operations, ISU/UI Study Group, University of lowa College of Public Health, lowa City, 2002.

[35] O.A. Sadik, W.H. Land Jr., J. Wang, Targeting Chemical and Biological Warfare Agents at the Molecular Level, Electroanalysis, 15 (2003) 1149-1159.

[36] J. Shah, E. Wilkins, Electrochemical Biosensors for Detection of Biological Warfare Agents, Electroanalysis, 15 (2002) 157-167.

[37] E. Herrero, L.J. Buller, H.D. Abruña, Underpotential Deposition at Single Crystal Surfaces of Au, Pt, $\mathrm{Ag}$ and Other Materials, Chem. Rev., 101 (2001) 1897-1930.

[38] H.F. Waibel, M. Kleinert, L.A. Kibler, D.M. Kolb, Initial Stages of Pt Deposition on Au(111) and Au(100), Electrochim. Acta, 47 (2002) 1461-1467.

[39] F. Nasirpouri, Electrodeposition of 2D and 3D Meso and Nanostructures, Springer Ser. Surf. Sci., 2017, pp. 123-185.

[40] E. Sheridan, J. Hjelm, R.J. Forster, Electrodeposition of Gold Nanoparticles on Fluorine-Doped Tin Oxide: Control of Particle Density and Size Distribution, J. Electroanal. Chem., 608 (2007) 1-7.

[41] J.J. Burk, S.K. Buratto, Electrodeposition of Pt Nanoparticle Catalysts from $\mathrm{H} 2 \mathrm{Pt}(\mathrm{OH}) 6$ and Their Application in PEM Fuel Cells, J. Phys. Chem. C, 117 (2013) 18957-18966. 
[42] A.J. Bard, L.R. Faulkner, Electrochemical Methods: Fundamentals and Applications, John Wiley New York, 2001.

[43] U. Schroder, J.D. Wadhawan, R.G. Compton, F. Marken, P.A.Z. Suarez, C.S. Consorti, R.F. de Souza, J. Dupont, Water-Induced Accelerated Ion Diffusion: Voltammetric Studies in 1-Methyl-3-[2,6-(S)dimethylocten-2-yl]imidazolium Tetrafluoroborate, 1-Butyl-3-Methylimidazolium Tetrafluoroborate and Hexafluorophosphate Ionic Liquids, New J. Chem., 24 (2000) 1009-1015.

[44] D.S. Silvester, A.J. Wain, L. Aldous, C. Hardacre, R.G. Compton, Electrochemical Reduction of Nitrobenzene and 4-Nitrophenol in the Room Temperature lonic Liquid [C4dmim][N(Tf)2], J. Electroanal. Chem., 596 (2006) 131-140.

[45] J. Lee, K. Murugappan, D.W.M. Arrigan, D.S. Silvester, Oxygen Reduction Voltammetry on Platinum Macrodisk and Screen-Printed Electrodes in Ionic Liquids: Reaction of the Electrogenerated Superoxide Species with Compounds used in the Paste of Pt Screen-Printed Electrodes?, Electrochim. Acta, 101 (2013) 158-168.

[46] S. Domínguez-Domínguez, J. Arias-Pardilla, Á. Berenguer-Murcia, E. Morallón, D. Cazorla-Amorós, Electrochemical Deposition of Platinum Nanoparticles on Different Carbon Supports and Conducting Polymers, J. Appl. Electrochem., 38 (2008) 259-268.

[47] M.N. Dešić, M.M. Popović, M.D. Obradović, L.M. Vračar, B.N. Grgur, Study of Gold-Platinum and Platinum-Gold Surface Modification and its Influence on Hydrogen Evolution and Oxygen Reduction, J. Serb. Chem. Soc., 70 (2005) 231-242.

[48] M.I. Awad, M.S. El-Deab, T. Ohsaka, Tailor-Designed Platinum Nanoparticles Electrodeposited onto Gold Electrode Catalytic Activity for Oxygen Reduction, J. Electrochem. Soc., 154 (2007) B810-B816.

[49] H. Angerstein-Kozlowska, B.E. Conway, W.B.A. Sharp, The Real Condition of Electrochemically Oxidized Platinum Surfaces: Part I. Resolution of Component Processes, J. Electroanal. Chem. Interfacial Electrochem., 43 (1973) 9-36.

[50] D. Pletcher, S. Sotiropoulos, Hydrogen Adsorption-Desorption and Oxide Formation-Reduction on Polycrystalline Platinum in Unbuffered Aqueous Solutions, J. Chem. Soc. Faraday Trans., 90 (1994) 36633668.

[51] J. Lee, D.S. Silvester, Low-Cost Microarray Thin-Film Electrodes with Ionic Liquid Gel-Polymer Electrolytes for Miniaturised Oxygen Sensing, Analyst, 141 (2016) 3705-3713.

[52] T.J. Davies, R.G. Compton, The Cyclic and Linear Sweep Voltammetry of Regular and Random Arrays of Microdisc Electrodes: Theory, J. Electroanal. Chem., 585 (2005) 63-82.

[53] J.G. Huddleston, A.E. Visser, M.W. Reichert, H.D. Willauer, G.A. Broker, R.D. Rogers, Characterization and Comparison of Hydrophilic and Hydrophobic Room Temperature lonic Liquids Incorporating the Imidazolium Cation, Green Chem., 3 (2001) 156-164.

[54] X. Ji, D.S. Silvester, L. Aldous, C. Hardacre, R.G. Compton, Mechanistic Studies of the Electrooxidation Pathway of Ammonia in Several Room-Temperature lonic Liquids, J. Phys. Chem. C, 111 (2007) 9562-9572.

[55] X. Ji, C.E. Banks, D.S. Silvester, L. Aldous, C. Hardacre, R.G. Compton, Electrochemical Ammonia Gas Sensing in Nonaqueous Systems: A Comparison of Propylene Carbonate with Room Temperature Ionic Liquids, Electroanalysis, 19 (2007) $2194-2201$.

[56] M.T. Carter, J.R. Stetter, M.W. Findlay, V. Patel, Printed Amperometric Gas Sensors, ECS Trans., 50 (2012) 211-220.

[57] J.F.M. Oudenhoven, W. Knoben, R. van Schaijk, Electrochemical Detection of Ammonia Using a Thin Ionic Liquid Film as the Electrolyte, Procedia Eng., 120 (2015) 983-986. 